\title{
ERRATUM
}

\section{Aeolian influx and related environmental conditions on Gran Canaria during the early Pleistocene - ERRATUM}

Inmaculada Menéndez, José Mangas, Esperança Tauler, Vidal Barrón, José Torrent, Juan F. Betancort, Ángelo Santana, José Manuel Recio, Luis A. Quevedo-González, Ignacio Alonso, Jorge Méndez-Ramos

DOI: https://doi.org/10.1017/qua.2018.64, Published by Cambridge University Press, 15 August 2018.

In the original publication of this article, there was a discrepancy between the title and running head of the article. The correct title and running head should read as follows: Aeolian influx and related environmental conditions on Gran Canaria during the early Pleistocene.

The publisher apologizes for this error.

\section{REFERENCE}

Menéndez, I., Mangas, J., Tauler, E., Barrón, V., Torrent, J., Betancort, J., ... Méndez-Ramos, J., 2018. Aeolian influx and related environmental conditions on Gran Canaria during the early Pleistocene. Quaternary Research 91(1), 35-50. doi:10.1017/qua.2018.64. 